\section{Carta de Paulo a Filemon: Ataque ao Estatuto Jurídico da Escravidão no Império Romano Sob a Ótica da Ética do Amor Cristão}

\section{Resumo}

O presente artigo tem por objetivo analisar a posição do Apóstolo Paulo na sua Carta a Filemon em defesa do escravizado fugitivo Onésimo. Por meio da utilização de argumentos teológicos e jurídicos, este artigo procura demonstrar que a carta tem natureza abolicionista, na medida em que subverte a legislação romana escravocrata para exigir que Filemon receba o escravizado Onésimo não mais como escravo, mas como irmão amado. Com isso, Paulo exige que Filemon substitua o rigor da legislação pela ética do amor cristão.

Palavras-chave: Apóstolo Paulo. Carta a Filemon. Escravidão. Abolicionismo. Ética Cristã. Amor.

\section{Abstract}

This article aims to analyze the Apostle Paul's position in his Letter to Philemon in defense of fugitive enslaved Onesimus. Through theological and legal arguments, this article seeks to demonstrate that the Letter is abolitionist in nature, as it subverts Roman slave legislation to require that Philemon receive the enslaved Onesimus no longer as a slave, but as a beloved brother. Thus, Paul demands that Philemon replace the rigor of legislation for ethics of Christian love.

Keywords: Apostle Paul. Letter to Philemon. Slavery. Abolitionism. Christian Ethic. Love.
Prof. Dr. Ivan de

Oliveira Durães

Pós-doutor em Direitos

Humanos pela Universidade de Coimbra. Pós-doutor em

Ciências da Religião pela

Universidade Presbiteriana

Mackenzie. Pós-doutor em

Antropologia pela Pontifícia

Universidade Católica de

São Paulo (PUC-SP). Doutor

e mestre em Direito. Mestre

em Ciências da Religião.

Bacharel em Direito, Filosofia

e Teologia. Professor em

cursos de Graduação,

Especialização, Mestrado

e Doutorado em Direito e

em Ciências da Religião

e Filosofia. Membro da

Accademia Napoletana,

Nápoles, Itália. Autor de

vários livros e

artigos científicos. 


\section{Introdução}

O presente artigo tem por objetivo investigar a posição do Apóstolo Paulo a respeito da escravidão em sua Carta a Filemon. Ao longo do texto, analisou-se a escravidão como instituto jurídico amplamente recepcionado na cultura romana antiga, pois, infelizmente, até mesmo cristãos dos primeiros séculos acolheram a ideia de que era possível tornar-se cristão e manter pessoas escravizadas.

Para alcançar o propósito da pesquisa, o primeiro item deste ensaio aborda o escravismo no sistema jurídico romano, com destaque para as normas que instituíam a escravidão, bem como as maneiras de seres humanos tornarem-se propriedade de outrem. Neste particular, verificou-se que o direito romano criou várias regras para disciplinar o escravismo.

Posteriormente, o texto enfrenta particularidades das epístolas paulinas, bem como o ambiente histórico-teológico de composição da Carta a Filemon, com destaque para o fato de que, em Roma Antiga, era comum que pessoas escravizadas procurassem líderes religiosos para mediassem nos conflitos existentes entre cativos e senhores. Notadamente, diante de episódios de fuga.

Por fim, segue-se a abordagem dos trechos da Carta em que Paulo, na manifesta defesa de Onésimo, enfrenta o sistema escravista romano, por meio de um conjunto de argumentos destinados ao estabelecimento do ethos do amor cristão em substituição à legislação romana e o seu rigorismo em relação aos escravizados fugitivos.

Este é o desenho externo do presente artigo. Sigamos ao seu conteúdo nos seguintes itens.

\section{Estatuto Jurídico da Escravidão na Roma Antiga}

Para levantar a discussão do cativeiro de humanos a partir da Carta de Paulo a Filemon, mostra-se necessária a análise do instituto da escravidão no momento da composição da missiva e o respectivo encaminhamento aos seus primeiros leitores. Eis o esforço deste item.

O abminável fato da escravidão não se trata de episódios isolados estabelecidos na realidade de povos que a ela se recorreram como mecanismo econômico para a designação de seres humanos como objetos de propriedade. Nas organizações estatais, antigas e modernas, em que se instituiu o escravismo, foram criadas diversas normas jurídicas e sociais para a sua acomodação. Em Roma Antiga não foi diferente, pois encontram-se em seu sistema jurídico um conjunto de diretrizes a respeito do escravismo.

Na Roma Antiga, a prática da escravidão era recorrente desde o século IX a.C., apesar de a ideia de liberdade (libertas), ser considerada "[...] o maior bem para o romano. A condição de homem livre domina todo o mundo antigo, inclusive o império romano, em que a liberdade se opõe à escravidão" (CRETELLA JR, 1993, p. 90).

Havia um fator muito curioso na prática do escravismo romano. O escravo era obrigado a render-se ao culto da família em que ele estava inserido. Com isso, observa-se o encontro entre a religião e a escravidão. Cada família romana tinha a sua religião doméstica, os seus próprios deuses. "Fora do lar o homem não sentia deus; o deus do vizinho era-lhe um deus hostil. O homem amava então a sua casa como hoje ama a sua igreja" (COLANGES, 2011, p. 126)

A propriedade imobiliária que o cativo tinha acesso era tão sagrada que diante da possibilidade de o seu senhor envolver-se em dívidas, prestava-se reverência à máxima do direito romano: "[...] o corpo do homem [do senhor] responde pela dívida, mas não a terra, porque ela é inseparável da família". (COLANGES, 2011, p. 91) Nessa toada, para que o escravizado nela habitasse, era preciso passar por um ritual sagrado de sua inserção na família de seu senhor, passando aquele a pertencer aos deuses familiares daquele que the detinha a propriedade.

Para o escravizado, "[...] a religião era uma cadeia que o prendia. Estava ligado à família por toda a vida e mesmo pelo tempo que lhe seguia a morte". (COLANGES, 2011, p. 144) Em decorrência 
disso, o escravo sujeitava-se ao poder do pater-familias,' um sacerdote que the impunha obrigações nesta vida e no além-túmulo. Com o passar do tempo, o cativo deixou a condição jurídica de membro da família, para sofrer a destinação de coisa "[...] de que o senhor podia dispor como entendesse" (SOUZA, 1910, p. 45).

Com a reclassificação jurídica expressa, o escravizado perdeu a sua humanidade na cultura e no direito romanos. Em consequência, aquele sistema jurídico criou princípios e normas destinados a inserir o cativo em contratos de compra e venda ${ }^{2}$, em inventários, em contratos de troca, locacão etc.

Peixoto (1955, p. 255) afirma que a legislação romana reservava ao cativo a mesma condição de um animal sujeito ao direito contratual e de propriedade. Nessa condição, "[...] o escravo não tem personalidade: servus nullum caput habet (GAIUS II, 16, de capitis minutione, 4)" (PEIXOTO, 1955 , p. 255). Por conta dessa manobra jurídica, "[...] o escravo não podia ter família e a união entre escravos ou de escravo ou escrava com pessoa livre de outro sexo era fato puramente material (contubérnio)" (PEIXOTO, 1955, p. 255).

Nem mesmo a fuga ou abandono do escravizado retirava-lhe a condição de objeto de propriedade, pois se isso viesse a ocorrer ele se tornava "[...] coisa sem dono (servus sine domino), de que qualquer um podia se apropriar" (PEIXOTO, 1955, p. 255) É lamentável observarmos a legislação ser utilizada como instrumento de opressão.

A partir da demonstração da desumanização imposta ao escravizado em Roma Antiga, seguem-se apontamentos a respeito

1 Pater-familias: expressão latina que significa ao chefe supremo da família, a qual todos os seus membros estavam a ele sujeitos. O pater-familias detinha o poder de vida e morte de todos os membros da família. Assim, poderia ele deixar viver ou matar qualquer membro da família, fossem filhos, cônjuge, escravos ou demais agregados que estivessem sob o seu teto.

2 É possivel considerar que em Roma, "[...] como forma de controle, a escravidão aparece como uma relação de dependência cuja manutenção oscila entre o emprego da violência e a coerção legal e o recurso da cooptação de benefícios, como a concessão da liberdade" (JOLY, 2004, p. 105) das maneiras pelas quais um ser humano tornava-se escravo entre os romanos (SOUZA, 1910, p. 46).

\section{Escravatura Decorrente do Cativeiro Bélico}

A fonte primeira da escravidão foram as conquistas advindas das guerras, sendo que as investidas belicosas foram as principais fontes da escravatura romana (LÉVY-BRUHL, 1931, p. 146). A vida do prisioneiro de guerra era poupada para que, em troca, ele trabalhasse para o seu captor, nas exatas condições e interesses impostos pelo vencedor do conflito. Para os juristas romanos, já que o vencedor da guerra tinha o direito de matar o vencido, com muito mais razão poderia impor-lhe trabalhos forçados, fazendo do vencido objeto de propriedade. Traduzindo o seguinte princípio: o vencedor que pode o mais (tirar a vida), pode o menos (impor trabalhos forçados) ao vencido.

O escravizado tornava-se propriedade do Estado romano e, posteriormente, era vendido aos particulares, como forma de arrecadação de fundos ao tesouro de Roma (CRETELLA JR., 1993, p. 92).

Tamanha era a força bélica de Roma que, nos tempos da República, essa potência mundial tornou-se grande centro de comércio de cativos. Isso se deve, acreditamos, ao fato da abundância de escravizados em suas extensões territoriais. Há relatos de que, não raro, um único romano chegava a possuir entre dez mil a vinte mil cativos (MARQUARDT apud SOUZA, 1910, p. 44).

\section{Escravatura Hereditária: O Ventre Escravizado}

Havia uma fórmula romana que dispunha: os nascidos de "ventre escravo" também eram escravos. Dito em outras palavras: "[...] filho de escrava, escravo é, ou seja, não se leva em conta a condição paterna" (CRETELLA JR., 1993, p. 91) Com isso, impunha-se um princípio de direito de propriedade sobre os descendentes dos escravizados, segundo o qual o acessório (o filho), segue a sorte do principal (a mãe). Portanto, 
sendo a mãe escravizada, os seus filhos também estariam nessa mesma condição.

A regra de que o útero escravizado produziria filhos escravos era imposta a partir do nascimento. Desse modo, não importava se, em momento posterior, a mãe obtivesse a liberdade. "Este princípio, porém, foi modificado em favor da liberdade, considerando-se livres os filhos que nascessem de mulher que tivesse sido livre em qualquer momento da gestação" (SOUZA, 1910, p. 55).

\section{Escravidão Fundada em Causas de Natureza Civil}

Em antiga fase do direito romano (CRETELA JR, 1993 , p. 92) eram escravizados os estrangeiros que:

- Não se inscrevessem no censo;

- Não se inscreviam no serviço militar, bem como os soldados desertores;

- Não pagavam as dívidas ao credor, após a condenação judicial, no prazo de 90 dias;

- Eram pegos em flagrante delito no crime de furto.

Na fase posterior, havia as seguintes causas cíveis no direito romano que abriam espaço para a escravidão (CRETELA JR., 1993, p. 87):

- Aos condenados a trabalhos forçados em minas, pois esse tipo de condenação impunha, a princípio, a redução do condenado à condição de escravizado;

- Aos condenados à luta com animais no circo, operando-se a extinção da personalidade, impondo ao condenado à condição de escravo;

- Estabelecimento de relação sexual entre mulher livre e escravo, ficando aquela na condição de escrava do senhor do seu parceiro sexual, mediante ordem judicial;

- Ato de ingratidão do liberto diante do seu senhor. Nestes casos, a recondução do liberto a escravo dava-se somente perante o magistrado;
- Por meio de negócio jurídico em que uma pessoa livre se vendia como escrava.

No regime jurídico romano, pelo que se observa, havia várias formas de se reduzir uma pessoa à condição de escrava. Do ponto de vista técnico, os indivíduos que eram escravizados no território romano sofriam a capitis de minutio maxima, ocorrendo a perda do seu status libertatis.

Esse era o sistema jurídico em que se deu a escrita da Carta de Paulo a Filemon. Provavelmente, foram esses os pontos colocados em pauta diante da leitura dos primeiros destinatários da carta. Assim, apresentado o cenário, prossiga-se no item seguinte à análise do texto paulino.

\section{Epístola a Filemon: Características Essenciais}

O epistolário paulino, presente no que se convencionou denominar Novo Testamento, é bastante rico de detalhes que vão além de arrazoados teológicos. Encontramos nas Cartas de Paulo registros históricos relacionados aos costumes, estrutura social, privilégios nobiliárquicos, estrutura política, relacionamentos afetivos, condição da mulher na sociedade de então, ajuda mútua, viagens, técnica recursal em julgamentos, condição dos apenados em presídios, atos de violência etc. Assim, as cartas paulinas merecem atenção em aspectos para além do doutrinário, dada a riqueza de detalhes nelas inerentes.

Do ponto de vista literário, as cartas são gêneros discursivos, reconhecidas como fonte histórica relativamente a outros espaços e tempos, com a presença de atores e propósitos que o pesquisador deve estar atento quando da análise de tais documentos. ${ }^{3}$

3 Lembra Dórea (2012, p. 55): “[...] as cartas, entre outros aspectos, eram usadas como instrumentos de cunho administrativo e político, por chefes de Estado. Podiam assumir a faceta de relatório burocrático, contendo informações variadas, inclusive comerciais. Quando tomavam a feição de carta aberta, dotavam de caráter público pontos de vista individuais ou de grupos". 
Na tradição cristã, as cartas atribuídas à autoria de Paulo ${ }^{4}$ são tidas como inspiradas pelo Espírito Santo, de modo que, nessa linha de pensamento, os cristãos acreditam que ele foi um instrumento humano utilizado pelo Sagrado para relevar verdades e disposições doutrinárias para serem observadas pela cristandade através dos séculos. Por este motivo, os textos de Paulo, constantes no cânon, são atemporais, dada a sua obrigatoriedade aos destinatários originais e aos leitores subsequentes. Não é que se observa, por exemplo, quando um fiel tem acesso ao corpus epistolário de Vieira (2014), por mais que lá também sejam encontrados acervos doutrinários.

A Carta a Filemon faz parte do gênero carta pessoal ${ }^{5}$, pois é endereçada com o objetivo de influenciar o comportamento de uma pessoa, individualmente considerada, qual seja: Filemon, um cristão senhor de escravos. Nessa carta observa-se a intimidade entre o emissário e o destinatário final. O mesmo se vê nas cartas a Timóteo, em que Paulo o trata de modo carinhoso, deixando evidente que o primeiro leitor era o seu filho na fé. Por tal motivo, há um conjunto de conselhos ao jovem líder religioso.

4 No que tange ao acervo de cartas atribuídas a Paulo, vale considerar o seguinte: "Desde o Iluminismo (século 18), a maioria dos estudiosos concordam que Romanos, 1 e 2 Coríntios, Gálatas, Filipenses, 1 Tessalonicenses e Filemon foram definitivamente escritas pelo punho de Paulo. Alguns negam a autoria de Paulo nas epístolas aos Efésios, Colossenses e 2 Tessalonicenses. Outros discordam, e há justificativa erudita suficiente para utilizá-los ao esboçar a teologia de Paulo. Muitos especialistas modernos negam que Paulo tenha escrito as chamadas Epístolas Pastorais (1 e 2 Timóteo, Tito). No entanto, estudiosos como D. Guthrie e E. Ellis insistem que a autoria de Paulo é totalmente viável - os documentos afirmam que Paulo escreveu-as e inclusive as pesquisas que não tinham a intenção de provar que Paulo havia escrito as Pastorais acabaram por evidenciar que ele deve ter escrito. Tendo por base fundamentos puramente eruditos, não é irresponsabilidade resumir a teologia de Paulo a partir do conjunto das trezes epístolas do Novo Testamento" (ELWELL; YARBROUGH, 1998, p. 258).

5 Para demais detalhes a respeito das cartas pessoais e de suas características morfológicas e conteúdos recorrentes, leia Silva (2002) - especialmente o capítulo 3.
Provavelmente, Paulo escreveu a Filemon no período em que ele estava preso em Roma. Portanto, por volta do ano 60 d.C. O objetivo da Carta é a obtenção de salvo-conduto ao escravizado fugitivo Onésimo para que, nesta condição, ele não sofresse castigos a mando de seu senhor, Filemon. Então, essa pequena epístola diz respeito à manifestação intercessora de Paulo para que legislação punitiva romana não fosse aplicada em desfavor de Onésimo, caso Filemon assim o quisesse.

Pelo enredo da Carta, vale aqui destacar um fato histórico: na cultura romana era comum os escravizados procurarem sacerdotes para intercederem junto aos senhores tanto para abrandamento ou ainda para a não aplicação de castigos (ELWELL; YARBROUGH, 1998, p. 323). Não sabemos se Onésimo procurou Paulo em decorrência de sua influência espiritual sobre o cristão Filemon, convertendo-se posteriormente ao cristianismo. Igualmente não dá para saber se Onésimo, simplesmente, foi preso e, por acaso, encontrou Paulo na prisão. A Carta não revela esse interessante detalhe.

Feitas estas considerações preliminares, sigamos para o próximo item, em que se analisa a posição de Paulo a respeito da escravidão a partir do conjunto de argumentos constantes na epistola a Filemon.

\section{A Oposição Paulina à Escravidão a partir de sua Defesa de Onésimo}

Na pequena Carta de Paulo a Filemon, encontram-se alguns pontos interessantes em que, aparentemente, o apóstolo flerta com a escravidão. ${ }^{6}$ Mas, numa leitura mais detida, com o contexto da época em mente, é possível compreender que Paulo segue na contramão

6 A dubiedade da interpretação da Carta a Filemon, em que alguns comentaristas afirmam que o Apóstolo defendeu, por meio dela, a escravidão, seguida por aqueles que entendiam em sentido contrário, pode ser observada na pesquisa de Elliott (1998, p. 40). 
das práticas escravocratas de seu tempo e faz um ataque subliminar à escravidão.

A Carta a Filemon trata-se, em verdade, de uma pequena circular endereçada ao cristão Filemon, aos irmãos Áfia, Arquipo e também à comunidade de cristãos da igreja local que se reunia na casa do primeiro. Foi elaborada com destinatários múltiplos, embora o texto faça alusão a um problema particular a ser enfrentado por Filemon. Trata-se de uma carta que cativa o leitor desde os primeiros versos, conforme destaca John Knox (1959, p. 10).

Na Carta, Paulo dá instruções a um proprietário de escravos que, nesta condição, exercia o papel de liderança em uma comunidade cristã. Nos primeiros versos da Carta é possível observar a autoridade do Apóstolo sobre o cristão Filemon, tanto é que após a saudação costumeira, assim pontua: "[...] mesmo tendo em Cristo plena liberdade para mandar que você cumpra o seu dever, prefiro fazer um apelo com base no amor" (FM, 8-9). Com esse apontamento, a Carta ganha característica de quase um bilhete pessoal (CONF. DODD, 1929, p. 1.292).

Antes de explanar as instruções a Filemon, o autor da Carta arroga para si a autoridade do seu apostolado, afirmando que poderia, de fato, estruturar as orientações a serem seguidas no formato de uma ordem expressa, pois destaca que teria liberdade para mandar. No entanto, prefere fazer um apelo com base no amor. Vale lembrar que, no seio do cristianismo, um apelo com base no amor tem um efeito devastador, impedindo a recusa por parte do destinatário da instrução.

Diante de um apelo formulado com base no amor, Filemon não teria alternativa. $O$ que the restava era cumprir, dado o mandamento do amor cuja observação é fundamental à rotina dos cristãos e das comunidades cristãs em formação no seio do Império Romano. Este tinha o seu poder com base na força; o cristianismo, por outro lado, seguia o mandamento do amor que constrangia e impunha aos seus praticantes o exercício de ações práticas inadiáveis para os vocacionados à ética cristã
O efeito prático do apelo de Paulo é que Filemon, colocado à prova pelo mandamento do amor, deveria receber o escravo fugitivo Onésimo a partir da ética cristã - e não sob a ética escravagista do Império Romano. Ou seja, o alicerce da recepção do escravo fugitivo seria o amor, hábil para constranger Filemon a comportar-se em sentido contrário ao que propunha o escravagismo em voga nos tempos da Carta.

De acordo com a legislação escravista de Roma, os fatos narrados na Carta a Filemon abririam espaço para as seguintes consequências:

- O escravizado Onésimo, ao ser devolvido ao seu senhor, estaria sujeito ao rigor da Lei que abria espaço para açoites e até a pena de morte de acordo com a decisão de Filemon;

- Paulo, que providenciou o retorno de Onésimo ao antro escravagista de Filemon, teria direito a receber uma recompensa pela manutenção da condição de submissão entre senhor e escravo. Assim, Filemon seria um devedor de Paulo.

Em resumo, na práxis romana, Onésimo devolvido ao cativeiro estaria sujeito às penalidades decorrentes de sua fuga, sendo que Paulo, por sua vez, deveria ser recompensado por Filemon. Este era o estado de coisas que a Carta ensejaria. Contudo, a dinâmica das palavras de Paulo segue em uma verdadeira proposta de contracultura.

O senhor de escravos, Filemon, foi constrangido a receber o escravizado Onésimo numa inversão da sua antiga condição jurídica imposta pelo Direito Romano. Observe-se, desde logo, as palavras contundentes de Paulo a respeito do novo status em que o fugitivo deveria ser recebido: "Mando-o de volta a você, como se fosse o meu coração" (FM, 12). Ora, com essa afirmação Paulo transfigura a relação jurídica de submissão outrora existente entre Filemon e Onésimo.

Nos papéis estabelecidos pelo Direito Romano, não havia espaço para receber um 
escravizado como se fosse o coração de um líder de notório respeito nas comunidades cristãs. Paulo, mesmo preso, era tido como uma autoridade para os cristãos, pois era ele um apóstolo. Então, o apelo de Paulo seguia no sentido de que Filemon recebesse Onésimo não mais com base na antiga relação jurídica firmada com fundamento no Direito Romano. Mas, o recebesse como o coração do próprio Paulo, uma autoridade.

A inversão proposta (na verdade, imposta pela autoridade de Paulo) é que Onésimo não fosse recebido com base no direito de propriedade (relação escravizado/senhor), mas com base no mandamento do amor, em toda a sua subversão. Sim, a proposta paulina é subversiva, pois procura estabelecer um novo vínculo entre Onésimo e Filemon. Para que não restem dúvidas desse novo estado de coisas contido na Carta, Paulo enfatiza:

Talvez ele [Onésimo] tenha sido separado de você por algum tempo, para que você o tivesse de volta para sempre, não mais como escravo, mas muito além de escravo, como irmão amado. Para mim ele é um irmão amado, e ainda mais para você, tanto como pessoa quanto como cristão. (FM, 15-16)

Paulo apela para Filemon receber o escravizado fugitivo, Onésimo, não mais como escravo, mas como um irmão. Há, ainda, uma ênfase neste adjetivo: Onésimo deveria ser recebido como irmão amado. Com isso, há pistas de que Filemon deveria libertar Onésimo e inseri-lo entre os da família da fé, como um irmão amado. $\mathrm{O}$ acolhimento do fugitivo deveria ser com outro status jurídico. O escravizado agora seria considerado um irmão amado, que carregava simbolicamente o coração de Paulo.

Vale observar com atenção: Paulo não está a indagar que Filemon deveria somente dispensar as punições impostas a um escravizado fugitivo. Paulo, a partir do mandamento do amor, exige que Filemon altere a relação jurídica mantida anteriormente com Onésimo, concedendo-lhe a condição de irmão amado, portador ainda de uma singularidade, o coração do apóstolo. Essa simbologia é marcante e bem demonstra o caráter antiescravagista da Carta a Filemon.

Se não bastasse, em uma atitude revolucionária para a época em que estava em prática o rigor romano para com os escravos (sobretudo, para com os fugitivos), Paulo ressalta: "[...] assim, se você me considera companheiro na fé, receba-o, como se estivesse recebendo a mim" (FM, 17). Esta passagem é manifestadamente antiescravista, pelos seguintes motivos:

- Paulo era um cidadão romano, e mesmo preso mantinha esta condição relevante para a realidade jurídica do Império. Assim, do ponto de vista secular, Onésimo deveria ser recebido como se um cidadão romano fosse. Isto the impunha uma mudança significativa em seu status jurídico. Deveria, assim, o fugitivo ser recebido com privilégios na casa de Filemon, resultando também uma condição diferenciada entre os membros da comunidade local. Com essa mudança proposta, Onésimo não deveria suportar o estigma da escravidão, o que seria, no sistema jurídico da época, impraticável a um cidadão romano;

- Por fim, Onésimo deveria ser recebido em amor, como um irmão amado. Mas, mesmo nessa condição que, por si só, orienta um novo status, deveria ele ser recebido com a mesma consideração que a comunidade instalada na casa de Filemon tinha em relação ao Apóstolo Paulo. Ou seja, o mesmo amor da comunidade dispensada ao Apóstolo, deveria ser direcionado a Onésimo. Esse senso de representatividade é tão intenso que Paulo chega a escrever: "Se ele [Onésimo] o prejudicou em algo ou deve alguma coisa a você, ponha na minha conta" (FM, 18). Nestas palavras, Paulo apresenta-se, ainda, como fiador de Onésimo. Uma manifestação de cuidado extremo que não encontra suporte na ética escravagista romana, mas com nítido apoio na ética antiescravagista do cristianismo. 
Pelo exposto, não há espaço para se sustentar que a Carta a Filemon apresente defesa aberta à escravidão. Em verdade, ela contém um sonoro modelo de rejeição ao escravismo, instituindo uma nova relação entre os protagonistas da Carta, não mais a de senhor e escravizado. Mas, a de membros da mesma família da fé, inaugurando novos papéis vinculados amorosamente ao padrão da ética do Calvário.

\section{Considerações Finais}

A Carta de Paulo a Filemon é instigante e merece reflexão atenta por parte de todos aqueles que se dedicam ao estudo da ética cristã e também de temas relacionados ao posicionamento do cristianismo com a escravidão.

Ao longo de nossa investigação, chegamos à conclusão de que a Carta de Paulo a Filemon é manifestadamente antiescravista, pois o Apóstolo Paulo exige que o senhor de escravos receba a Onésimo, escravizado fugitivo, como irmão amado, em uma típica espécie de salvo-conduto. Desse modo, Paulo exige que Filemon ao invés de punir Onésimo, acolha-o em amor, atribuindo a este a dignidade e urgência semelhante a reservada a um apóstolo.

Pelo conjunto de informações constantes na Carta de Paulo a Filemon, apesar de posicionamentos em sentido contrário, chegamos à conclusão de que o Apóstolo procurou alterar o ethos da relação senhor-escravizado, em rejeição à rigidez da legislação romana vigente à época da composição da missiva em defesa de Onésimo. Em lugar das sanções aplicáveis a um escravo fugitivo, Paulo ordena, com base no amor, a inserção de Onésimo na família da fé, com as dignidades inerentes a esta condição inaugurada pela ética cristã.

\section{Referências Bibliográficas}

BÍBLIA SAGRADA. Nova versão internacional. Trad. Comissão da Sociedade Bíblica Internacional. São Paulo: Vida, 2000.
Novo Testamento interlinear: grego-português. Barueri, SP: Sociedade Bíblica do Brasil, 2004.

COLANGES, F. de. A cidade antiga: estudo sobre o culto, o direito e as instituições da Grécia e de Roma. Trad. José Cretella Jr.; Agnes Cretella. São Paulo: Revista dos Tribunais, 2011.

CRETELLA JR., J. Curso de Direito Romano. São Paulo: Forense, 1993.

DODD, C. H. Introduction. In: Abingdon Bible Commentary. Nashville: [s.n.], 1929.

DÓREA, J. Cartas de Eurico Alves: fragmentos da cena modernista. Feira de Santana, BA: UEFS, 2012.

ELLIOTT, N. Libertando Paulo: a justiça de Deus e a política do apóstolo. São Paulo: Paulus, 1998.

ELWELL, W. A.; YARBROUGH, R. W. Descobrindo - Novo Testamento: uma perspectiva histórica e teológica. São Paulo: Cultura Cristã, 1998.

JOLY, F. D. Tácito e a metáfora da escravidão: um estudo da cultura política romana. São Paulo: Edusp, 2004.

KNOX, J. Philemon among the letters of Paul: a new view of its place and importance. New York: Abingdon, 1959.

LÉVY-BRUHL, H. Théorie de l'Esclavage. Revue Générale du Droit, de la Legislation et de Jurisprudence, n. 55, 1937.

PADRE ANTONIO VIEIRA. Obra completa epistolografia. t. 1. v. 1-5. São Paulo: Loyola, 2014. PEIXOTO, J. C. de M. Curso de Direito Romano. Rio de Janeiro: Haddad, 1955.

SILVA, J. Q. G. Um estudo sobre o gênero carta pessoal: das práticas comunicativas aos indícios de interatividade na escrita dos textos. 2002. Tese (Doutorado) - Faculdade de Letras da Universidade Federal de Minas Gerais, 2002.

SOUZA, M. E. História das instituições: Direito Romano, Peninsular Português. Coimbra, Portugal: França Amado, 1910. 